\title{
¿PUEDEN LOS DERECHOS NATURALES HACER ALGUNA CONTRIBUCIÓN A LA FILOSOFÍA DE LOS DERECHOS HUMANOS?
}

\author{
Julio MONTERO \\ CONICET \\ Universidad de Buenos Aires \\ jmnormandia@gmail.com
}

\begin{abstract}
RESUMEN: Durante décadas, los filósofos han concebido los derechos humanos como una clase de derechos naturales de los que gozamos por el mero hecho de ser seres humanos. Sin embargo, esta interpretación ha sido severamente cuestionada en los últimos años. Toda una familia de autores, identificados con una concepción "práctico-dependiente", asevera que los derechos humanos constituyen una práctica sui generis completamente ajena a la tradición del derecho natural. En contra de esta postura, este artículo argumenta que el discurso de los derechos naturales es parte constitutiva de la doctrina actual de los derechos humanos y que puede hacer un aporte crucial a la adecuada justificación y comprensión de sus funciones, su contenido y su alcance normativo. Más concretamente, mi tesis será que si bien los derechos humanos no pueden reducirse a derechos naturales, bien podrían derivar de derechos naturales previos.
\end{abstract}

PALABRAS CLAVE: dignidad, universalidad, justificación, concepciones prácticas de los derechos humanos, concepciones naturalistas de los derechos humanos

SUMMARY: For decades, philosophers tended to think about human rights as natural rights that we enjoy just in virtue of our common humanity. However, in recent years, this view has been persistently challenged by a group of authors defending an alternative "practice-dependent" approach. According to them, contemporary human rights constitute a sui generis practice which is completely foreign to the natural rights tradition. Contrary to this claim, this article argues that natural rights discourse is an integral part of current human rights doctrine and that it may help us understand and justify the functions, content and normative reach of human rights norms. More concretely, my thesis is that although human rights are not reducible to natural rights, they may nevertheless derive from natural rights which are prior to them.

KEY WORDS: dignity, universality, justification, practical conceptions of human rights, naturalistic conceptions of human rights

\section{Introducción}

El concepto de derechos humanos es uno de los más importantes en nuestro repertorio moral. Está a la par de otras nociones clave, como las de justicia, igualdad y democracia; pero es también un concepto sumamente opaco. Desde la adopción misma de la Declaración Universal, filósofos, abogados y activistas discuten sobre sus funciones, su alcance normativo, y su contenido. En la bibliografía reciente es- 
tas discusiones han tendido a ordenarse en torno a dos concepciones opuestas de los derechos humanos. En general, se las designa como concepciones "naturalistas" y concepciones "prácticas", "políticas" o "práctico-dependientes". A pesar de sus importantes diferencias, ambas corrientes pretenden ofrecer una interpretación filosófica de la práctica de los derechos humanos reconocidos por el derecho internacional que sea capaz de explicar sus rasgos más distintivos y nos brinde orientación para dirimir controversias acerca de su naturaleza y su condiciones de aplicación. ${ }^{1}$

La concepción naturalista hunde sus raíces en la filosofía política moderna. Siguiendo el sendero desbrozado por John Locke en su Segundo tratado sobre el gobierno civil, los autores naturalistas conciben los derechos humanos como derechos naturales (Locke 1988). Desde esta perspectiva, los derechos naturales se definen por las siguientes características:

(1) Son derechos de los que gozamos por el mero hecho de ser seres humanos.

(2) Son derechos que preservan ciertos intereses fundamentales de la persona humana.

(3) Son derechos que protegen los intereses fundamentales de la persona humana contra la actividad de cualquier otro agente.

(4) Son derechos universales aplicables en todo tiempo y lugar; por lo tanto, gozaríamos de su protección incluso en un hipotético estado de naturaleza en el que no hubiera instituciones políticas.

En el debate contemporáneo, esta concepción fue defendida por autores sumamente influyentes. Así, por ejemplo, Alan Gewirth argumenta que los derechos humanos resguardan nuestra capacidad para la acción intencional. Su tesis es que para poder actuar como verdaderos agentes, los seres humanos debemos gozar de dos clases de bienes: "bienes genéricos" y "bienes aditivos". Los bienes genéricos son la libertad y el bienestar, mientras que los bienes aditivos abarcan la educación, el autorrespeto, y la posibilidad de desarrollar ciertas virtudes de carácter que incrementan nuestra capacidad para obrar como agentes propositivos (Gewirth 1982, pp. 51-66). A su vez, estos

${ }^{1}$ Este estado de la cuestión no pretende ser exhaustivo. En el debate actual existen muchas concepciones alternativas de los derechos humanos, incluyendo concepciones teleológicas, costructivistas, y positivistas. En este artículo abordaré sólo las que parecen haber adquirido mayor influencia en la discusión anglosajona actual. 
bienes fundan un listado de derechos humanos de igual contenido, que impone a todo agente el deber de respetarlos y de contribuir a satisfacerlos en la medida de sus posibilidades (Gewirth 1982, p. 64).

Otro destacado representante de la tradición naturalista es James Griffin. En su libro On Human Rights, Griffin define los derechos humanos como estándares que protegen la condición de persona, bajo el supuesto de que ser una persona en sentido pleno implica ser capaz de imaginar un plan de vida propio y de actuar para realizarlo (Griffin 2008 , p. 32). En su opinión, esta aptitud para inyectar valor a la existencia a través de proyectos propios es el bien que más valoramos, a tal extremo que adquiere prioridad sobre la felicidad misma (Griffin 2008, p. 33). Por su parte, la noción de persona puede descomponerse en tres componentes que constituyen condiciones necesarias para la agencia normativa. Esos componentes son: (1) la autonomía requerida para escoger metas propias; (2) la libertad necesaria para perseguir las metas que nos hemos propuesto; y (3) una provisión mínima de recursos que nos permita realizar elecciones genuinas, incluyendo acceso seguro a educación, alimentación y servicios de salud (Griffin 2008, p. 33). Al combinarse con una serie de consideraciones prácticas generales, estos componentes de la condición de persona generan un abanico de derechos humanos semejante - aunque no completamente idéntico - al reconocido por los instrumentos internacionales actuales (Griffin 2008, pp. 191-211).

Finalmente, Martha Nussbaum se refiere a los derechos humanos como normas que protegen ciertas capacidades "con una importancia central para la vida humana, al margen de qué otras cosas la persona elija o persiga" (Nussbaum 1997, p. 286). Estas capacidades incluyen: vivir una vida humana completa, gozar de seguridad y salud, ser capaz de desarrollar vínculos emocionales y aptitudes creativas y tener la oportunidad de llevar una vida sexual satisfactoria, entre otras más (Nussbaum 2002, pp. 129-130). Si bien por razones prácticas la responsabilidad primordial de promover el florecimiento de estas capacidades recae en los estados, Nussbaum sostiene que los derechos humanos imponen deberes a todos los agentes que puedan ayudar a realizarlos.

Como vemos, a pesar de sus variaciones de matiz, las concepciones naturalistas de los derechos humanos combinan tres módulos. El primero es una visión filosófica más o menos elaborada de la persona humana y sus intereses de orden superior. Esta suerte de antropología normativa es una constante en el discurso de los derechos naturales desde la aparición del derecho natural moderno. El segundo módulo es una concepción de los derechos que resultan necesarios para 
preservar esos intereses, incluso en una situación prepolítica. Por lo general, esos derechos se derivan de la concepción de la persona humana adoptada en conjunción con una serie de consideraciones empíricas sobre nuestra constitución biológica y psicológica y sobre el modo en que interactuamos en diversos contextos. El tercer módulo es una teoría de la responsabilidad que asigna a todos los agentes, tanto naturales como artificiales, obligaciones de respetar y promover esos derechos de acuerdo con su capacidad. ${ }^{2}$

A pesar de su popularidad y su atractivo, la concepción naturalista ha sido severamente cuestionada por una familia de autores que propone una concepción "práctica", "política" o "práctico-dependiente". $\mathrm{Su}$ argumento es que los derechos humanos internacionales constituyen una práctica sui generis que no guarda relación con categorías morales previas. En consecuencia, para comprender cabalmente esta práctica debemos tratar de identificar el rol funcional que las normas de derechos humanos desempeñan en la vida política contemporánea (Rawls 1999a, p. 78; Raz 2010, pp. 327-329; Sangiovanni 2008, p. 152; Beitz 2009, p. 102). Y, de acuerdo con estos autores, dicho rol no es preservar ciertos intereses de la persona humana en general, sino restringir el comportamiento de los estados modernos mediante la imposición de sanciones a los gobiernos que los infrinjan (Rawls 1999a, p. 80; Raz 2010, p. 328; Sangiovanni 2008, p. 153; Beitz 2009, p. 109).

En virtud de esta tesis fundamental, los promotores de la concepción práctica concluyen que la tradición del derecho natural no tiene nada que aportar a la comprensión de los derechos humanos internacionales. Más todavía, sostienen que cualquier intento de concebirlos en esos términos sólo puede generar confusión y desviar a la práctica de sus objetivos constitutivos. Esta posición ha sido sucintamente resumida por Andrea Sangiovanni en el siguiente pasaje:

El reclamo de los derechos humanos [...] se dirige a la comunidad global, la cual se supone que está ahora bajo una obligación de reconocer y ayudar a individuos y grupos que puedan sustentar correctamente sus demandas de protección en una concepción de los derechos humanos. Hay poco que anude las razones para recurrir al lenguaje de los derechos naturales en el periodo moderno temprano y nuestra propia búsqueda actual de estándares internacionales para criticar el amplio abanico de instituciones domésticas, trans-, inter-, y supranacionales. (Sangiovanni 2008, p. 153)

${ }^{2}$ Véase sobre este punto Montero, inédito. 
Y un poco después concluye:

es un error concebir los derechos humanos como "atemporales", en el sentido de que pudieran usarse para orientar nuestra evaluación de la conducta humana en, digamos, la antigua Babilonia. Los regímenes actuales de derechos humanos presuponen la ornamentación del estado moderno [...]. De hecho, su rol en este contexto es mitigar las peores consecuencias para el bienestar humano que podrían surgir de sistemas políticos con precisamente esas características. Concebirlos como una subespecie de derechos naturales, una vez más, malinterpreta la necesidad de contar con instrumentos de derechos humanos en la práctica internacional y global. (Sangiovanni 2008, p. 153)

En contra de esta opinión, la tesis central de este artículo es que el discurso de los derechos naturales puede hacer una contribución valiosa a la filosofía de los derechos humanos. En este sentido, mi argumento será que aunque los derechos humanos no pueden reducirse a derechos naturales, hay razones de peso para no descartar completamente la perspectiva naturalista a la hora de construir una concepción filosófica de esta práctica contemporánea. Más concretamente, trataré de probar que si prescindimos de toda referencia a los derechos naturales, algunos aspectos cruciales de la práctica de los derechos humanos se vuelven difíciles de explicar.

El artículo está organizado de la siguiente manera. En la sección que sigue intentaré señalar cuatro aportes cruciales que el discurso de los derechos naturales puede hacer a una teoría de los derechos humanos. En especial, sostendré que los derechos naturales pueden ayudar a iluminar las funciones y el contenido de los derechos humanos internacionales, justificando su universalidad y garantizando cierta coherencia con la doctrina actual. A su vez, en las secciones siguientes consideraré dos posibles objeciones contra mi planteamiento: la primera sostiene que la idea misma de derechos naturales es un sinsentido, mientras que la segunda alega que el discurso de los derechos naturales provee un fundamento inadecuado para los derechos humanos en un mundo signado por el hecho del pluralismo. Aunque estas objeciones no han sido explícitamente articuladas por los defensores de la concepción política, es de gran importancia abordarlas dada su gran influencia en el pensamiento filosófico y su directa relevancia para este debate. 


\section{2 . ¿Que contribución pueden hacer los derechos naturales?}

Hay al menos cuatro contribuciones decisivas que el discurso de los derechos naturales puede hacer a una concepción filosófica de los derechos humanos. Si bien estas contribuciones están evidentemente relacionadas, por razones de claridad argumentativa me gustaría abordarlas por separado.

\subsection{Coherencia con la práctica}

La primera contribución es garantizar cierta coherencia con la doctrina actual de los derechos humanos. Como los defensores del enfoque práctico han argumentado insistentemente, los derechos humanos no son lo mismo que los derechos naturales. Por el contrario, representan demandas que las personas tienen contra agentes oficiales. En su entrada de la Stanford Encyclopedia of Philosophy, James Nickel lo expone en estos términos:

los derechos humanos son normas políticas que se refieren principalmente a cómo las personas deben ser tratadas por sus gobiernos. No son normas morales ordinarias que aplican a la conducta interpersonal (como la prohibición de mentir o ejercer violencia). En palabras de Thomas Pogge, "para ser relevante desde una perspectiva de derechos humanos, una conducta debe ser oficial en algún sentido". (Nickel 2014, p. 3)

Esta tesis parece inmediatamente ratificada por el hecho de que muchos de los derechos reconocidos por el derecho internacional actual no tendrían destinatarios claros en ausencia de un estado moderno. Así sucede, por ejemplo, con los derechos a la nacionalidad, al debido proceso y al gobierno representativo, entre otros (Beitz 2009, pp. 5459). Del mismo modo, todo el sistema de protección de los derechos humanos se orienta a monitorear la conducta de los estados, y las cortes de derechos humanos sólo admiten reclamaciones por violaciones de derechos humanos cuando están explícitamente dirigidas contra gobiernos (Donelly 1986).

Esto no implica, sin embargo, que los derechos naturales sean completamente ajenos a la práctica de los derechos humanos. De hecho, la doctrina de los derechos humanos está plagada de referencias naturalistas. La Declaración Universal, por ejemplo, habla de "la dignidad intrínseca de la persona humana y los derechos iguales e inalienables de todos los miembros de la familia humana" (Preámbulo). El Pacto de Derechos Civiles y Políticos afirma que los derechos 
humanos "derivan de la dignidad intrínseca de la persona humana" y vuelve a hacer mención de "los derechos iguales e inalienables" que asisten a todos los seres humanos por igual. Expresiones similares se repiten en otros documentos, como el Pacto de Derechos Económicos, Sociales y Culturales, la Convención para la Eliminación de Todas las Formas de Discriminación Contra la Mujer, y el Pacto de los Derechos de la Niñez. Y un documento mucho más reciente, como la Declaración de Viena, reafirma la tesis de que "todos los derechos humanos derivan de la dignidad y el valor inherentes a la persona humana" (Preámbulo).

Las consideraciones anteriores nos permiten concluir que la idea de los derechos naturales es una parte constitutiva de la doctrina de los derechos humanos, y que para los propios redactores de dicha doctrina los derechos humanos guardan algún lazo conceptual con la tradición del derecho natural (Gilabert 2011, pp. 446-448; Wellman 2011, pp. 3-16; Morsink 1999, pp. 281-284). Aunque ambas nociones no sean equivalentes, no es irrazonable suponer que los derechos humanos derivan de derechos naturales previos. Si es así, la reflexión sobre los derechos naturales podría tal vez brindarnos una valiosa orientación para superar controversias sobre su verdadera naturaleza, su contenido y el alcance de su aplicación.

Me gustaría ilustrar esta conclusión mediante algunos ejemplos. Desde hace varios años se debate intensamente sobre las obligaciones de las corporaciones transnacionales. Si bien en 2011 las Naciones Unidas elaboraron una serie de directrices al respecto, la discusión continúa abierta. En este sentido, muchos expertos alegan que los únicos agentes obligados por las normas de derechos humanos son los estados en su calidad de firmantes de los instrumentos pertinentes. Así, cuando incumplen con su deber de proteger a la población de las actividades de actores privados que operan dentro de su jurisdicción, la responsabilidad por las violaciones resultantes recae directamente sobre ellos. Sin embargo, las corporaciones multinacionales a menudo desarrollan sus actividades en el contexto de estados que carecen de la capacidad real de controlarlas, volviendo obsoleto el sistema de protección. La tesis de que los derechos humanos derivan de derechos naturales podría ayudarnos a saldar esta controversia. Si la interpretación que propongo resulta convincente, se haría evidente que, al menos en ciertos casos, las corporaciones podrían ser susceptibles de que se le impusieran sanciones bajo el derecho internacional por lacerar los intereses fundamentales de las personas, o, por lo menos, que la comunidad internacional tendría la responsabilidad de emprender acciones al respecto. 
El segundo ejemplo que quiero considerar se relaciona con los debates sobre derechos humanos y pobreza global. No necesito decir que este campo de discusión es particularmente escabroso y ha despertado gran interés en los últimos años. Mientras algunos autores sostienen que los derechos humanos generan un deber urgente de adoptar medidas para combatir la pobreza extrema a escala mundial (Pogge 2002; Salomon 2007), otros argumentan, en cambio, que la asistencia a los países pobres sólo puede concebirse como un vago deber de ayuda humanitaria o de asistencia (Nagel 2005; Rawls 1999a). Una vez más, la referencia a los derechos naturales puede iluminar este debate con una nueva luz. Es posible que, por razones prácticas y hasta normativas, los deberes correspondientes a los derechos de subsistencia recaigan sobre cada uno de los estados considerados separadamente. Pero si los derechos humanos mantienen un vínculo conceptual con los derechos naturales, no sería irrazonable concluir que la comunidad internacional tienen la obligación de brindar ayuda a los países que no dispongan de los recursos para honrar sus compromisos más fundamentales. Así, la referencia al sustrato naturalista nos permitiría dar sentido práctico al principio de cooperación internacional contenido en la Carta de Naciones Unidas y en varios documentos adicionales.

\subsection{Justificación}

La segunda contribución que los derechos naturales pueden hacer se ubica en el plano de la justificación. Existe entre los teóricos un acuerdo generalizado respecto de que los derechos humanos constituyen una clase especial de derechos, a saber: derechos de los que las personas gozan al margen de su nacionalidad, origen étnico, género, religión, etc. Puede que no sean atemporales, pero pretenden ser universales al menos en un sentido más restringido: toda persona que habita el mundo tal como lo conocemos goza de su protección. En palabras de Nickel, "los derechos humanos son normas internacionales que abarcan a todos los países y a todas las personas" (Nickel 2014, p. 3). Por consiguiente, ningún gobierno puede negarse a respetar los derechos humanos de sus residentes, excepto quizá en situaciones de emergencia rígidamente estipuladas por el derecho internacional.

La noción de derechos naturales parece relevante para justificar este rasgo distintivo de los derechos humanos. Es cierto que una comunidad política puede decidir que hay ciertos derechos que los gobiernos surgidos de mayorías ocasionales no pueden violar. Muchas 
veces, esos derechos se incluyen en una constitución y se faculta a las cortes para que los preserven de las decisiones políticas ordinarias. Pero esto no agota el concepto de derechos humanos. Incluso en el marco del derecho internacional positivo, los derechos humanos se presentan como restricciones absolutas a la autodeterminación de los pueblos que se sustraen de la agenda política, de la deliberación pública y de la voluntad soberana de las naciones. Ni siquiera una asamblea constituyente dotada de la máxima legitimidad democrática puede desconocerlos. Este rasgo de los derechos humanos internacionales parece apuntalar mi tesis. Si los derechos humanos tienen una naturaleza incondicionada y universal, deben derivarse de derechos morales previos que resguardan ciertos intereses de la persona en un sentido más general.

Hay dos modos alternativos de resistir esta conclusión. El primero consiste en replicar que la autoridad de los derechos humanos surge de acuerdos puramente legales alcanzados en el plano internacional. Desde esta perspectiva de corte positivista, los derechos humanos son vinculantes porque la comunidad internacional ha decidido convertir el respeto a estas normas en una condición para el reconocimiento de la soberanía de los estados (Nickel 2014, p. 3; Dworkin 2013). De hecho, esta interpretación es compartida por muchos expertos, y tiene la evidente ventaja de que desliga la autoridad de los derechos humanos de toda controversia ética, metafísica o religiosa. Dado que la comunidad internacional ha acordado mayoritariamente adoptar los instrumentos de derechos humanos, los estados deben honrarlos si desean gozar de los beneficios derivados de la cooperación entre pueblos. No hay ninguna necesidad de recurrir a derechos morales previos para justificar su universalidad.

Al margen de sus atractivos, la interpretación positivista enfrenta graves problemas. Supongamos, por ejemplo, que por alguna razón el proceso de adopción de la Declaración Universal hubiera fracasado. Aun así, sería razonable sostener que los estados deben respetar los derechos fundamentales de sus residentes, y que si se niegan a hacerlo su legitimad podría verse socavada. De ser éste el caso, el derecho internacional no habría creado los derechos humanos de la nada. Simplemente se habría limitado a institucionalizarlos, explicitarlos y dotarlos de mecanismos de implementación. Tal vez por esta razón la Declaración Universal se presenta abiertamente como un documento que "reconoce" derechos previos, y no como una instancia de creación originaria de esos derechos (Wellman 2011, cap. 1; Nickel 2014, pp. 6-8). 
De igual modo, la interpretación positivista podría tener dificultades para dar cuenta de la autoridad de los propios instrumentos internacionales. Así, por ejemplo, no le resultaría fácil explicar por qué los estados que se negaran a suscribir tales instrumentos podrían sufrir sanciones o ser marginados por la comunidad internacional. En este sentido, no bastaría con señalar que la mayoría de los estados se ha puesto de acuerdo en promover los derechos humanos incluso entre aquellos pueblos que los rechazan (Dworkin 2013). Esto sería como justificar la decisión de castigar a alguien que se niega a practicar cierta religión alegando que la mayoría de sus conciudadanos la considera la religión verdadera. Para justificar la autoridad universal de los derechos humanos debemos recurrir a razones objetivas externas a toda convención o acuerdo legal. De lo contrario, estaríamos ante una instancia de imposición por la fuerza. Y los derechos naturales parecen capaces de proveernos de la clase de razones que necesitamos.

Si para evitar esta consecuencia se sostuviera, en cambio, que los derechos humanos sólo son vinculantes para aquellos estados que han suscrito los documentos pertinentes, entonces cualquier estado podría verse libre de sus compromisos retirándose de los tratados. $\mathrm{Y}$, en ese caso, la práctica de los derechos humanos dejaría de ser universal, perdiendo uno de sus rasgos más distintivos y buena parte de su interés práctico. Todo esto parece sugerir que la universalidad de los derechos humanos presupone un sustrato normativo previo a la práctica misma. Es a causa de que las personas gozan de ciertos derechos, los cuales preservan sus intereses fundamentales de las actividades de todo agente, que los estados deben respetar sus derechos humanos al margen de cualquier otra consideración.

El segundo modo de resistir la conclusión de que los derechos humanos guardan relación con los derechos naturales propone concebirlos como normas que pertenecen de modo exclusivo al campo de la moralidad política. Esta tesis se puede explicar mejor trazando un paralelo con la noción de justicia. Si bien la justicia constituye un valor moral suprapositivo, suele pensarse que es aplicable únicamente al modo en que se ordena la estructura básica de una sociedad. ${ }^{3} \mathrm{Y}$ esto significa que es un valor distintivamente político, un valor que no tiene consecuencias directas sobre las acciones de las personas. Siguiendo este paralelo, los derechos humanos podrían verse como derechos morales que se dirigen sólo a los estados y a otros agen-

\footnotetext{
${ }^{3}$ Éste es un presupuesto ampliamente aceptado, al menos entre los filósofos políticos de raigambre rawlsiana.
} 
tes similares. Así, la vinculación con los derechos naturales se vería conceptualmente interrumpida sin incurrir en una interpretación positivista y sin menoscabar su universalidad.

Esta opción ha sido examinada por autores como Joshua Cohen en su obra The Arch of Moral Universe (Cohen 2010, cap. 10). En su versión de la concepción práctica, los derechos humanos expresan condiciones para la pertenencia o la inclusión en una sociedad políticamente organizada. Más concretamente, la tesis de Cohen es que sólo cuando una sociedad respeta nuestros derechos humanos, nos trata como miembros plenos. Cuando, por el contrario, nos niega el acceso seguro a los bienes y libertades que los derechos humanos comprenden, nos trata "como extranjeros, personas cuyo bien puede ser dejado de lado al diseñar leyes y políticas públicas: excluidos que no tienen ningún papel que desempeñar en su sociedad política" (Cohen 2010, p. 239). El criterio de pertenencia o inclusión es, por supuesto, de naturaleza normativa y, como tal, no depende de actos positivos de reconocimiento. Pero es, al mismo tiempo, un criterio distintivamente político que no se deduce, al menos en principio, de derechos morales previos.

Esta segunda estrategia tampoco es concluyente. El derecho puramente político, por ejemplo, a no ser torturado parece imposible de justificar a menos que invoquemos derechos morales más generales. Si alguien preguntara por qué el gobierno de un país debe abstenerse de torturar a sus residentes, podríamos tal vez responder que respetar esta norma es una condición necesaria para que el gobierno sea justo, goce de legitimidad o trate a todos sus habitantes como miembros. Pero este nuevo enunciado requiere justificación. Y para justificarlo tarde o temprano deberemos recurrir al argumento de que hay ciertos intereses de la persona que todo el mundo debe respetar. A modo de ilustración, podemos imaginar el siguiente diálogo entre un defensor de los derechos humanos y un detractor de esta causa:

Defensor: Los estados deben respetar los derechos humanos de sus habitantes.

Detractor: ¿Por qué?

Defensor: Porque el respeto a los derechos humanos es una condición necesaria para que los estados gocen de legitimidad, o para que traten a sus residentes como verdaderos miembros.

Detractor: ¿¿Por qué los derechos humanos habrían de ser condiciones necesarias para la legitimidad de los estados, o para 
que los estados traten a sus residentes como verdaderos miembros?

Defensor: Porque los derechos humanos abarcan ciertos intereses fundamentales de la persona que, dada su crucial importancia, todo agente debe respetar. ${ }^{4}$

Si este diálogo imaginario captura adecuadamente la secuencia argumentativa que normalmente seguiríamos, el vínculo conceptual entre derechos humanos y derechos naturales sería imposible de interrumpir. Incluso una concepción que presente los derechos humanos como estándares de moralidad política parece descansar implícitamente sobre un sustrato normativo naturalista más amplio.

Por supuesto, nada de lo anterior implica sostener que los derechos humanos son derechos naturales. La tesis que trato de defender es más modesta. Sostiene simplemente que los derechos humanos pueden derivarse de derechos naturales previos sin que haya una reducción conceptual de unos a otros. El hecho de que muchos de los derechos reconocidos por el derecho internacional actual presupongan la existencia de instituciones políticas modernas no clausura esta posibilidad. Los derechos humanos bien podrían ser aplicaciones de derechos naturales más generales a circunstancias concretas.

Para dar credibilidad a esta idea, supongamos que las personas gozaran de un derecho natural a la independencia personal. Éste es un derecho que yace en el corazón mismo del programa liberal y que puede rastrearse en la filosofía política de varios autores modernos. Así, Locke afirma que "criaturas del mismo rango y especie [...] deben también ser iguales entre sí sin que haya subordinación ni sujeción de unas a otras", y que ningún ser humano debe ser sometido a la voluntad de terceros (Locke 1988, p. 269). De igual modo, en su Metafísica de las costumbres, Kant sostiene que "la libertad (la independencia con respecto al arbitrio constrictivo de otro) [...] es el único derecho originario que corresponde a todo hombre en virtud de su humanidad" (Kant 1996, p. 393 [AA 6: 237]). En la filosofía de Kant, este derecho implica que toda persona es libre de perseguir sus

\footnotetext{
${ }^{4}$ Este enunciado presupone, desde luego, que el deber de respetar esos intereses fundamentales se corresponde con derechos correlativos que sus titulares pueden reclamar. Aunque no todo deber se corresponde con un derecho, el presupuesto parece pertinente en este contexto. No es controvertido pensar que el deber de su vecino de no matarlo se corresponde con un derecho suyo de exigirle que no lo mate. Y tampoco es controvertido pensar que si su vecino lo mata, viola sus derechos además de incumplir con su obligación.
} 
propias metas sin sufrir interferencias de otros, a condición de que respete el igual derecho de los demás (Ripstein 2009, pp. 30-57). ${ }^{5}$

Aunque desde la perspectiva de Kant el derecho a la independencia parece una mera restricción lateral a la acción, en clave contemporánea podría interpretarse como un derecho más robusto. En esta dirección, algunos autores proponen comprenderlo como un derecho a disponer de las condiciones necesarias para concebir y perseguir nuestros propios fines sin ser sometidos a la voluntad de terceros. Desde esta perspectiva, el derecho natural a la independencia sería un derecho a gozar de una esfera protegida de agencia personal para realizar planes de vida libremente escogidos (Valentini 2012; Montero 2016).

Naturalmente, en ausencia de una autoridad común, este requerimiento parece imposible de satisfacer. De hecho, ningún individuo dispone de las capacidades necesarias para asegurar al resto de las personas las protecciones, oportunidades y recursos que la satisfacción de este derecho exige. Aun así, el derecho natural a la independencia podría conservar cierta tracción normativa incluso en el estado de naturaleza. Es evidente que este derecho impone a todos un deber de no subyugar a los demás. Y, al mismo tiempo, como pensaba Kant, podría también justificar un deber positivo de abandonar el estado de naturaleza y construir una autoridad común capaz de resguardar la independencia de todos (Kant 1996, p. 456 [AA 6: 313]). Esta tesis no es del todo extraña en el debate contemporáneo. Después de todo, en su Teoría de la justicia, Rawls postula un deber natural de sostener y respetar instituciones justas ya existentes, así como de contribuir a crearlas cuando éstas no existan todavía (Rawls 1999b, p. 99).

Bajo este esquema, los derechos humanos podrían interpretarse como las condiciones que un agente político con las capacidades de un estado debería cumplir para respetar la independencia de las personas sometidas a su autoridad. Sólo cuando el estado nos garantiza una esfera robusta de agencia personal, para perseguir nuestras metas sin vernos sometidos al arbitrio de otros, goza de legitimidad. Así, los derechos humanos no serían lo mismo que el derecho natural a la independencia. El derecho a la independencia sería previo y más fundamental, y los derechos humanos surgirían de ese derecho una vez que un agente con la capacidad de satisfacerlo hubiera sido creado.

${ }^{5}$ Es importante aclarar que estoy postulando la existencia de este derecho natural sólo a modo ilustrativo. El objetivo es mostrar cómo los derechos humanos podrían derivar de derechos naturales previos. Pero establecer la existencia efectiva de un derecho natural a la independencia requiere una discusión adicional. Véase al respecto Montero 2016. 
El derecho a la independencia podría justificar tres derechos humanos abstractos dirigidos contra los estados, a saber: (1) el derecho a la libertad; (2) el derecho a la participación política; y (3) el derecho a los medios de subsistencia. Es evidente que estas categorías de derechos son indispensables para preservar la independencia personal. El derecho a la libertad es fundamental para perseguir nuestras metas sin sufrir interferencias por parte de terceros. El derecho a la participación política es crucial para evitar que acabemos persiguiendo metas unilateralmente fijadas por otros, ya se trate de mayorías políticas o de elites gobernantes. Y el derecho a los medios de subsistencia es necesario para nuestra existencia continuada como agentes propositivos y para planificar nuestras vidas y proponernos objetivos a largo plazo (Ripstein 2009, pp. 267-300; Valentini 2012). A su vez, estos derechos humanos abstractos podrían dar lugar a derechos humanos más específicos dependiendo de las circunstancias sociales vigentes. Por ejemplo, en las condiciones actuales, podrían generar derechos a la libertad de prensa, al debido proceso, a la seguridad social y a formar sindicatos.

Es importante aclarar, por supuesto, que el modelo que acabo de proponer no pretende ofrecer una teoría completa de los derechos humanos. Simplemente pretende ilustrar la tesis de que los derechos naturales bien pueden operar como un estrato de justificación atemporal más fundamental del que podrían derivarse derechos más específicos como los que reconocen los instrumentos internacionales. La derivación de cada uno de esos derechos exige, naturalmente, un trabajo de argumentación más exhaustivo del que puedo ofrecer aquí. Sin embargo, si el argumento es más o menos convincente, abre una opción conceptual que muchos defensores del enfoque práctico han considerado inviable: los derechos humanos pueden surgir de derechos naturales previos sin verse reducidos a éstos. ${ }^{6}$

\subsection{Funciones}

El tercer aporte que los derechos naturales pueden hacer es contribuir a explicar las diversas funciones que los derechos humanos desempeñan en la vida política contemporánea. Éste es un aporte sumamente importante. Como sostienen los defensores del modelo práctico, la capacidad de una teoría para dar cuenta de los rasgos principales de la práctica es un criterio de éxito casi decisivo. De hecho, si una interpretación filosófica de una actividad humana no puede justificar sus características más salientes, tendríamos razones

\footnotetext{
${ }^{6}$ Para un desarrollo pormenorizado de esta tesis, véase Montero 2016.
} 
para sospechar que se trata de una construcción abstracta desligada de la realidad. En consecuencia, ninguna concepción que no supere esta prueba puede tenerse en pie. Y, a la inversa, la capacidad de un modelo teórico para acomodar armoniosamente las funciones de la práctica contaría como una importante ventaja respecto de visiones rivales (Raz 2010, pp. 327-328).

Hay razones de peso para pensar que la referencia a los derechos naturales puede ser de ayuda en este aspecto. Por lo general, los defensores del enfoque práctico sostienen que las normas de derechos humanos regulan exclusivamente el trato que los gobiernos dan a sus residentes (Beitz 2009, pp. 122-125; Raz 2010, p. 328; Sangiovanni 2008, p. 154). Si bien admiten que las violaciones a los derechos humanos pueden generar razones para que actores externos emprendan acciones al respecto, la función primordial de los derechos humanos es de corte interno: constituyen estándares de comportamiento para los estados y sus gobiernos. En consecuencia, bajo esta interpretación, los derechos humanos no serían aplicables a actores no estatales, a organismos internacionales o a estados que realizaran actividades fuera de sus fronteras (Montero 2014). Pero esta tesis resulta inconsistente con el derecho internacional actual.

De acuerdo con la mayoría de los expertos, las normas de derechos humanos tienen un impacto normativo sobre el comportamiento extraterritorial de los estados y sobre las instituciones de gobernanza global (Clapham 2006, pp. 110-136; Lafont 2010, p. 204; Glanville 2012). Así, por ejemplo, ningún estado puede violar los derechos humanos de extranjeros bajo su control ni fuera de su territorio. ${ }^{7} \mathrm{De}$ igual modo, instituciones como el Fondo Monetario Internacional, el Banco Mundial y la Organización Internacional del Comercio están supeditadas a la Carta de Naciones Unidas y deben respetar directrices de derechos humanos cuando diseñan sus políticas generales (Clapham 2006, pp. 137-157). Por último, algunos autores sugieren que, en virtud del principio de cooperación internacional contenido en la Carta y en varios instrumentos, los países ricos deben brindar asistencia a las naciones que no disponen de los medios para satisfacer los derechos humanos de su población, adoptando medidas proactivas para fortalecer sus capacidades y disminuir la pobreza (Salomon 2007, pp. 64-101; Pogge 2002, pp. 64-65).

${ }^{7}$ Un ejemplo paradigmático de esto es el de las personas que el gobierno de los Estados Unidos mantiene ilegalmente detenidas en su base extraterritorial de Guantánamo. 
A partir de las consideraciones precedentes, se vuelve evidente que los derechos humanos no se orientan simplemente a regular el comportamiento interno de los estados, sino que expresan una preocupación más amplia por los intereses fundamentales de la persona humana. Es precisamente por esta razón que, en determinadas circunstancias, pueden imponer obligaciones a actores no estatales, supraestatales y cuasiestatales. En consecuencia, no es irrazonable pensar que los derechos humanos son normas que derivan de un sustrato normativo más fundamental. Si bien los derechos humanos y los derechos naturales no constituyen categorías equivalentes, los derechos naturales podrían contribuir a justificar el alcance que se atribuye a las normas de derechos humanos en el derecho internacional actual.

Hay, sin embargo, una variante de la concepción práctica que podría acomodar mejor las funciones que los derechos humanos desempeñan. Me refiero a la concepción cosmopolita de los derechos humanos desarrollada por Thomas Pogge en su libro World Poverty and Human Rights (Pogge 2002). De acuerdo con esta teoría, los derechos humanos representan exigencias que se dirigen, no a cualquier agente en general, sino exclusivamente a sistemas institucionales coercitivamente impuestos sobre los seres humanos. Más concretamente, estos reclamos exigen que todo régimen social coercitivo se organice de modo tal que todos sus miembros gocen de acceso seguro al objeto de sus derechos humanos en la medida de lo posible (Pogge 2002, p. 64.) Desde esta perspectiva, cuando un esquema coercitivo priva a las personas de acceso seguro a los objetos de sus derechos humanos de un modo previsible y evitable viola un deber negativo, comparable al deber de no dañar (Pogge 2002, pp. 66-67). Y esto genera, por supuesto, deberes urgentes de compensación que Pogge propone descargar creando un fondo global antipobreza financiado mediante un impuesto al uso de los recursos naturales (Pogge 2002, pp. 204-215).

La concepción cosmopolita tiene la ventaja de que permite ampliar considerablemente las funciones de los derechos humanos. Desde esta perspectiva, los organismos internacionales, las instituciones de gobernanza global, las fuerzas de ocupación, los grupos armados que controlan un territorio y los estados que actúan fuera de su propia jurisdicción estarían obligados a respetarlos. Al mismo tiempo, a diferencia de otras variantes de la concepción práctica, la concepción cosmopolita parece capaz de explicar por qué las normas de derechos humanos conservarían su fuerza normativa aun si el sistema de esta- 
dos se viera radicalmente alterado y se adoptaran nuevas formas de organización política. ${ }^{8}$

En respuesta a esta objeción, me gustaría señalar que las ventajas de la concepción cosmopolita dependen en gran medida de que ésta se compromete solapadamente con un derecho moral más fundamental. Se trata del derecho a que no se nos impongan reglas coactivas que afecten nuestro bienestar. $\mathrm{Y}$ es razonable suponer que, al igual que el derecho natural a la independencia, la fuerza normativa de este derecho es conceptualmente previa a la existencia de instituciones compartidas. De ser así, el argumento cosmopolita completo podría reconstruirse en estos términos:

(1) Toda persona goza del derecho a que no se le haga coerción de modos que afecten negativamente su bienestar.

(2) Cuando una estructura coercitiva interfiere con la satisfacción de los intereses fundamentales de sus miembros, viola sus derechos humanos.

(3) Los estados y el régimen internacional son estructuras coercitivas.

(4) Cuando los estados o el régimen internacional interfieren con la satisfacción de los intereses fundamentales de las personas, violan sus derechos humanos.

Como vemos, es precisamente la referencia a un derecho natural previo no explicitado, que en el argumento anterior se expresa en la premisa (1), lo que permite a la concepción cosmopolita acomodar más armoniosamente las funciones que los derechos humanos desempeñan en la vida política actual. Este derecho no parece surgir de relaciones especiales ni de vínculos asociativos. Es más bien un derecho moral universal que genera obligaciones especiales una vez que ciertas estructuras sociales se han puesto en funcionamiento. Y aunque Pogge sólo discute el asunto marginalmente, daría la impresión de que ese derecho más fundamental tiene implicancias normativas para todo agente aun en ausencia de instituciones comunes. ${ }^{9}$

${ }^{8}$ Véase una crítica de esta posición en Montero 2010.

${ }^{9}$ En esta dirección, Pogge sostiene: "Es difícil ver cómo uno puede, por un lado, comprometerse con la afirmación de que las personas no deben ser sometidas a trato inhumano o degradante y, al mismo tiempo, no considerar que es moralmente incorrecto que las personas traten a otros de maneras inhumanas o degradantes. Un compromiso con los derechos humanos va de la mano con compromisos morales interaccionales" (Pogge 2002, p. 65). 


\subsection{Contenido}

La última contribución que los derechos naturales pueden hacer es ayudarnos a precisar el contenido de los derechos humanos. En este sentido, parece imposible producir un listado de derechos humanos a menos que nos involucremos en una reflexión sobre la naturaleza de la persona humana y sus intereses de orden superior (Montero 2014; 2016).

Los defensores del enfoque práctico han sugerido el siguiente test para identificar las normas de derechos humanos y distinguirlas de otras normas: un derecho es un derecho humano si y sólo si su violación por parte de un gobierno justificaría la adopción de medidas correctivas a nivel internacional (Raz 2010, p. 334; Beitz 2009, p. 137). Dependiendo del autor, esas medidas pueden restringirse a sanciones coercitivas (Rawls 1999a, p. 105), o pueden abarcar también la rendición de cuentas, la exposición pública y la provisión de asistencia (Beitz 2009, pp. 115-116).

Este test tiene varios problemas. En primer lugar, como se ha señalado repetidamente, los derechos humanos cumplen una multiplicidad de tareas en el discurso práctico y nada permite concluir que su capacidad para atraer la atención internacional sea su rasgo más distintivo (Nickel 2006; Tasioulas 2009; Nickel 2014; Montero 2014). De hecho, la Declaración Universal los presenta como "estándares comunes que todos los pueblos y naciones deben procurar alcanzar". Nada en la Declaración ni en otros instrumentos avala la tesis de que un derecho califica como derecho humano sólo si su violación es capaz de justificar medidas correctivas por parte de otros agentes.

En segundo lugar, aun si los derechos humanos fueran esencialmente restricciones externas a la soberanía de los estados, el criterio propuesto sería insuficiente para delimitar su contenido. Es imposible decidir si la violación de cierto derecho podría justificar una respuesta externa si no recurrimos a una argumentación filosófica sobre la naturaleza de la persona humana y sus intereses fundamentales. Antes de resolver, por ejemplo, si la violación del derecho a no padecer tortura, a formar sindicatos, o a la libertad de expresión constituye un asunto adecuado de interés internacional, debemos decidir qué tan importantes son estos intereses para los seres humanos. Y esta tarea parece imposible de realizar si no recurrimos a alguna concepción general de la persona. De hecho, el modo más natural de explicar por qué un gobierno que viola ciertos derechos se vuelve vulnerable a sanciones externas es sostener que, al obrar de ese modo, socava algún interés 
especialmente importante de los seres humanos — precisamente la clase de interés que nadie debe socavar por ninguna razón.

Algunos autores han tratado de eludir esta objeción recurriendo a una estrategia alternativa. En su reciente libro The Idea of $\mathrm{Hu}$ man Rights, Charles Beitz sostiene que los derechos humanos son derechos que aspiran a proteger aquel grupo de intereses que "pueda ser reconocido como importante para un amplio rango de vidas posibles" (Beitz 2009, p. 139). En otras palabras, cierto derecho es un derecho humano si y sólo si personas con concepciones del bien diversas pudieran acordar que el interés que el derecho resguarda es verdaderamente importante. Así, la concepción política podría especificar el contenido de los derechos humanos sobre bases relativamente neutrales, evitando comprometerse con una concepción filosófica y hasta cierto punto metafísica de la persona.

Aunque ingeniosa, esta propuesta no puede prosperar. Cuando no se la complementa con alguna antropología moral, la idea de "intereses importantes" corre el riesgo de volverse vacía. En efecto, a menos que propongamos alguna concepción de la persona humana, parece imposible distinguir los intereses que son de hecho valorados por las personas y las culturas de los intereses que son verdaderamente fundamentales desde una perspectiva normativa. Después de todo, el hecho de que la gente valore algo no implica que lo que valora sea genuinamente valioso. Y, a la inversa, el hecho de que crea que algo carece de valor no implica que realmente carezca de valor (Gilabert 2011, p. 447). Los juicios de valor sólo pueden justificarse por referencia a consideraciones normativas independientes de las intenciones, deseos y creencias de los sujetos. Por consiguiente, la reflexión filosófica de corte naturalista parece ineludible si queremos evitar recaer en alguna variante de convencionalismo.

Hay una importante objeción que los defensores de la concepción política podrían formular contra mi planteamiento. Así, por ejemplo, Raz argumenta que no todos nuestros intereses pueden transformarse legítimamente en derechos (Raz 2010, p. 324). Los derechos presuponen la asignación de obligaciones correlativas, y esas obligaciones imponen costos a los demás que no siempre podemos justificar. Aun cuando las personas tengan un interés crucial en gozar de las condiciones para florecer como agentes autónomos, esto no basta para imponer al resto un deber de brindarles acceso a lo que necesitan.

Esta objeción afecta a una buena parte de las teorías naturalistas disponibles en la bibliografía reciente. Pero no es tan efectiva contra mi propuesta. En este sentido, el derecho natural a la independencia 
expresa una norma básica de respeto a los demás. En el estado de naturaleza sólo genera deberes negativos de no socavar activamente su autonomía, así como un deber positivo de contribuir a construir instituciones comunes que garanticen a todos una esfera adecuada de agencia personal. Si aceptamos que el interés de las personas en concebir y realizar sus propios planes de vida es moralmente relevante, estas dos obligaciones no parecen difíciles de justificar. De hecho, se trata de obligaciones más bien modestas. Es cierto que una vez que el estado existe, los derechos humanos generan deberes positivos más extensos. Pero los costos de satisfacerlos pueden distribuirse de un modo razonable entre sus miembros. Excepto por los libertarios, nadie pondría en duda esta transición de intereses a derechos.

Del mismo modo, si partimos del derecho natural a la independencia, podemos delimitar con cierta precisión el contenido de los derechos humanos. Esto se debe a que el derecho a la independencia no es un derecho a las condiciones para el florecimiento personal. Es tan sólo un derecho a gozar de una esfera de agencia individual que nos permita escoger planes propios y perseguirlos sin padecer interferencias arbitrarias y sin vernos sometidos al arbitrio de otros. Así, un estado que permita grandes desigualdades de riqueza o que no garantice una igualad plena de oportunidades, respetaría los derechos humanos de sus residentes a pesar de ser injusto. En consecuencia, la especial prioridad que asignamos a los derechos humanos en el razonamiento moral queda a resguardo del inflacionismo.

Nada de lo anterior pretende negar, desde luego, que cualquier intento de demarcar con precisión el contenido de los derechos humanos estará sujeto a controversias. Pero el hecho de que podamos discrepar razonablemente sobre lo que se requiere para respetar la independencia de las personas no nos autoriza a concluir que sea imposible alcanzar un acuerdo. Si estamos realmente interesados en los derechos humanos, no tenemos otra opción que jugar el juego de la argumentación. Y, en consecuencia, tenemos que hacer nuestro mejor esfuerzo para defender nuestras propuestas, considerar objeciones pertinentes y revisar nuestras posturas a la luz de ellas. Esto es lo que hacemos en cualquier otro campo de la actividad filosófica y ninguna teoría de los derechos humanos puede eludir esta exigencia.

\section{Un disparate en zancos}

En las secciones que siguen quiero considerar dos potenciales objeciones que podrían articularse contra la tradición del derecho natural y, por añadidura, contra la tesis más específica de que el discurso de 
los derechos naturales puede hacer un aporte valioso a la filosofía de los derechos humanos. Ninguna de ellas ha sido explícitamente formulada contra las concepciones naturalistas en el debate contemporáneo, pero se trata de objeciones poderosas y pertinentes a esta discusión. Por esa razón vale la pena abordarlas.

La primera de estas objeciones es bien conocida en la historia de la filosofía política. La objeción sostiene que la idea misma de derechos naturales es absurda. Más concretamente, el argumento es que no puede haber derechos en ausencia de instituciones políticas capaces de implementarlos y hacerlos cumplir. Una formulación clásica y concisa de esta tesis puede encontrarse en los escritos de Jeremy Bentham:

No hay algo así como derechos naturales, algo así como derechos anteriores al establecimiento de un gobierno, algo así como como derechos naturales opuestos a, o discernibles de, derechos legales: esta expresión es meramente figurativa; así, si se intenta darle un sentido literal, conduce al error, y a la clase de error que supone una jugarreta - una jugarreta extrema. (Bentham 1987, p. 52)

A partir de reflexiones como ésta, Bentham concluye que los derechos naturales no pueden ser otra cosa que "un disparate retórico, un disparate en zancos" (Bentham 1987, p. 53).

Esta objeción puede construirse de dos maneras. Según la primera interpretación, la idea misma de gozar de un derecho presupone que podamos reclamar ese derecho ante agentes capaces de hacerlo valer. Así, la existencia de instituciones adecuadas es una condición de posibilidad para la existencia de derechos. Cuando éstas no existen, los derechos se vuelven puramente aspiracionales: una mera descripción de estados de cosas ideales que desempeñan un papel expresivo y carecen de toda fuerza normativa (James 2003, pp. 136-147; O’Neill 2003, pp. 97-106).

Esta objeción está completamente desencaminada. Para ver por qué, imaginemos que hubiera un país cuyas instituciones fueran incapaces de proteger el derecho de las personas a no padecer tortura. Es evidente que esto no nos autorizaría a concluir que no gozan de un derecho a no ser torturadas. Entre los teóricos morales hay cierto consenso respecto de que, cuando están debidamente justificados, los derechos fundan reclamaciones que ofrecen razones para la acción (Gilabert 2011, p. 443; Meckled-García 2005, pp. 143-148). Por consiguiente, aun cuando no haya mecanismos institucionales efectivos a 
disposición, sostener que las personas gozan de un derecho a no padecer tortura genera razones para erigir agentes que puedan resguardar este derecho adecuadamente y para evaluar al sistema institucional como injusto o ilegítimo. Y, por supuesto, también genera razones para que los individuos se abstengan de afectar de manera arbitraria los intereses que ese derecho preserva. Es precisamente este rasgo lo que hace de los derechos dispositivos con capacidad crítica, potencia transformadora y gran interés práctico. Despojarlos de este atributo no sólo equivale a desnaturalizarlos, sino que vuelve ininteligible una parte considerable de la filosofía política y moral contemporánea.

Me gustaría considerar ahora la segunda variante de esta objeción. Ésta sostiene que incluso si los derechos pueden desempeñar un papel importante en ausencia de instituciones adecuadas, no podría haber derechos en un hipotético estado de naturaleza. Esto es así porque en semejante condición las personas no tendrían ninguna garantía de que los otros respetarán su integridad, su libertad y su independencia. Por consiguiente, estarían autorizadas a hacer cualquier cosa que consideren necesaria para sobrevivir. Desde esta perspectiva, el estado de naturaleza es un contexto amoral, una guerra de todos contra todos en la que el comportamiento ético es un lujo que bien puede costarnos la vida.

De acuerdo con esta nueva formulación de la objeción, la existencia de instituciones adecuadas no es una condición necesaria para la existencia de un derecho, pero la existencia de alguna clase de autoridad política es indispensable para que los derechos tengan sentido. Dado que, por definición, los derechos naturales son derechos que tendrían validez incluso en el estado de naturaleza, sería imposible justificarlos. No es necesario aclarar que esta objeción se inspira en la filosofía política de Thomas Hobbes y en los aportes de sus seguidores realistas (Hobbes 1982, caps. 13-15).

Aunque popular, esta manera de ver las cosas es sumamente problemática. Imaginemos que un ataque terrorista generara el colapso de nuestro mundo político: no hay cortes de justicia, no hay gobierno, no hay fuerzas de seguridad. Esta situación sería comparable al estado de naturaleza en la mayoría de los aspectos importantes. Es evidente que en un escenario así usted tendría permiso de dañar a cualquiera que representara un riesgo para usted o para su familia. Pero, tras una reflexión más cuidadosa, se daría cuenta de que incluso en esa situación usted no tendría permiso de hacer cualquier cosa. Habría ciertos límites morales que debería respetar. Por ejemplo, usted no debería dañar a personas que no representaran un riesgo. $\mathrm{Y}$ si no 
pudiera evitar dañar a otros, el daño debería ser más o menos proporcional al riesgo que representan. Del mismo modo, usted debería abstenerse de torturar o esclavizar a los demás, excepto quizá en situaciones extremas (Montero 2016).

$\mathrm{Si}$, como dijimos recién, la existencia de derechos morales depende de razones que los sustenten, los derechos pueden existir incluso en un hipotético estado de naturaleza: cualquier razón que ahora tengamos para respetar la dignidad de las personas sería operativa también en ausencia de instituciones políticas, al menos en principio (Locke 1988, cap. 2; Nozick 1974, pp. 28-51; Rawls 1999b, pp. 18-19). En este sentido, la mayoría de los dispositivos para la fundamentación de normas que los filósofos han inventado -incluidos el imperativo categórico, el cálculo de utilidad, la situación ideal de diálogo, y la perspectiva del observador imparcial - son insensibles al contexto institucional y a la existencia de autoridades políticas.

\section{Liberalismo, tolerancia y etnocentrismo}

La última objeción que quiero considerar sostiene que el discurso de los derechos naturales provee un fundamento inadecuado para la práctica de los derechos humanos, ya que es distintivo de la tradición liberal moderna y podría ser rechazado por personas y pueblos con concepciones morales alternativas. Esto sería, por cierto, una grave desventaja. Una concepción de los derechos humanos construida sobre bases partisanas no mostraría el debido respeto por el pluralismo y la diversidad cultural. De ser así, no sólo las comunidades no liberales, sino las propias sociedades liberales tendrían razones para rechazarla. Esta preocupación la ha expresado Rawls de un modo muy persuasivo:

Si se requiriera a todas las sociedades ser liberales, entonces la idea del liberalismo político fracasaría en mostrar la debida tolerancia por otras maneras aceptables [...] de ordenar la sociedad. Nosotros reconocemos que una sociedad liberal debe respetar las doctrinas comprehensivas de sus ciudadanos [...] a condición de que sean promovidas de maneras compatibles con una concepción razonable de la justicia [...]. De igual modo [...] siempre que las instituciones básicas de una sociedad no liberal conduzcan a su pueblo a honrar una ley razonable y justa para la Sociedad de los Pueblos, un pueblo liberal debe tolerarla y aceptarla. (Rawls 1999a, p. 60)

A esta consideración de principio puede sumarse otra de naturaleza puramente estratégica. Una concepción excesivamente liberal de los 
derechos humanos podría proporcionar una base sumamente inestable para la práctica asociada, ya que quizá sería incapaz de atraer un apoyo verdaderamente universal o al menos transnacional para ella.

En respuesta a esta última objeción vale la pena señalar que el discurso de los derechos naturales es, como espero haber mostrado, parte constitutiva de la doctrina actual de los derechos humanos. Las referencias de corte naturalista son ubicuas en los documentos internacionales y en los modos de argumentar y razonar de quienes participan en la práctica. Del igual modo, los derechos humanos presuponen una imagen de la persona humana como igual, libre y autónoma. Sin este presupuesto, la mayoría de los derechos consagrados por los instrumentos carecería de justificación. Por consiguiente, tal vez sea hora de aceptar que los derechos humanos tienen un sesgo mucho más liberal de lo que estamos dispuestos a reconocer. Antes de decidir si esta práctica está justificada, si es colonialista o si debe ser radicalmente reformada, conviene que comprendamos adecuadamente su naturaleza.

Nada de lo anterior impide, sin embargo, que personas con visiones alternativas puedan compartir el ideal que los derechos humanos encarnan. Muchas concepciones no liberales razonables pueden encontrar - o construir - su propia ruta justificativa hacia la imagen liberal de la persona humana y la idea subyacente de que las personas gozan de ciertos derechos por el mero hecho de ser seres humanos. Después de todo, la doctrina actual de los derechos humanos ya ha sido aceptada por casi todas las naciones y yace en el corazón mismo de la vida política internacional. Interpreto este hecho como una evidencia de que la idea que los derechos humanos presuponen puede convertirse en objeto de un amplio consenso superpuesto de alcance transcultural. ${ }^{10}$

Naturalmente, bien podría suceder que algunas tradiciones morales, políticas o religiosas extremas se negaran a ingresar a este consenso. Algunas de estas visiones sostienen, por ejemplo, que los seres humanos no tienen derechos, sino sólo obligaciones respecto de sus

\footnotetext{
${ }^{10}$ Tres datos adicionales pueden reforzar este punto. El primero es que muchas concepciones de los derechos naturales, como la de John Locke, se sostienen sobre concepciones religiosas. El segundo es que, de acuerdo con un estudio realizado por la UNESCO antes de la redacción de la Declaración Universal, las principales religiones y culturas disponen de elementos internos que podrían abonar la tesis de que los seres humanos gozan de ciertos derechos en virtud de su humanidad. El tercero es que el grupo encargado de redactar el borrador de la Declaración Universal era de naturaleza multicultural y fue sensible a las perspectivas surgidas de variados puntos de vista.
} 
comunidades; otras afirman que no son seres libres, sino sirvientes de dios o de alguna causa superior; y otras aseveran que no son iguales, sino partes de alguna jerarquía metafísica que les asigna un valor secundario.

No veo ninguna razón de peso para tener en cuenta doctrinas así cuando discutimos sobre la naturaleza de los derechos humanos. Incorporar esas visiones sería una traición a las convicciones liberales más fundamentales. El compromiso liberal con la tolerancia no es un compromiso de tolerar cualquier conducta, teoría o visión del mundo. Por el contrario, en el nivel más fundamental, el principio de tolerancia expresa un deber de respetar el igual derecho de los demás a vivir sus vidas de acuerdo con sus propias convicciones siempre que no dañen a terceros. Y este deber se funda, a su vez, en el principio de autonomía de la persona. Es precisamente porque respetamos la autonomía de los demás que tenemos razones para tolerar distintas concepciones del bien aunque nos resulten erradas o repulsivas. Y es por esta misma razón que tenemos razones para respetar a pueblos que ordenan su estructura básica por referencia a concepciones de la justicia que resultan parcialmente insatisfactorias desde una perspectiva liberal. El respeto por la autodeterminación de los pueblos es moralmente valioso porque representa un modo de respetar la autonomía de sus miembros.

Si el deber de tolerancia se deriva del principio de autonomía, entonces no debería conducirnos a tolerar a sociedades que socavan la autonomía de sus propios ciudadanos, impidiéndoles realizar planes de vida propios, practicar su religión, o expresarse libremente. Por el contrario, restringir el comportamiento de sociedades así parece un modo de tomarse en serio el valor de la tolerancia. Tal vez sea necesario, por razones prácticas, negociar con gobiernos opresores. Pero no tenemos por qué respetarlos o acomodarlos en el plano puramente filosófico.

\section{Conclusión}

La conclusión de este trabajo es doble. Los defensores del enfoque político están en lo cierto al sostener que los derechos humanos contemporáneos no son lo mismo que los derechos naturales. En este sentido, la práctica actual les asigna una función distintivamente política. No se trata de derechos que preserven los intereses fundamentales de la persona humana de las actividades de cualquier otro agente aun en el estado de naturaleza. A pesar de esto, es apresurado concluir que los derechos humanos constituyen una práctica completamente 
sui generis; que no guardan una ligazón conceptual y normativa con los derechos naturales; y que el discurso de los derechos naturales no puede hacer ninguna contribución a su comprensión. Por el contrario, espero haber probado que hay buenas razones para pensar que el discurso de los derechos naturales es una parte constitutiva de la doctrina actual de los derechos humanos, y que, lejos de generar confusión, este discurso puede ayudarnos a justificar sus funciones, definir su contenido, y dar sentido a la idea que encarnan.

Más que borrar los lazos de los derechos humanos con el derecho natural, el desafío para los teóricos de los derechos humanos es elucidar la relación exacta entre ambas categorías y determinar de qué modo el discurso de los derechos naturales puede proveer claves para interpretar el derecho internacional actual y saldar controversias sobre la naturaleza de los derechos humanos contemporáneos. Esta tarea queda pendiente. El único objetivo de este artículo es probar que ese camino es no solamente fructífero, sino además ineludible. ${ }^{11}$

\section{BIBLIOGRAFÍA}

Beitz, Ch., 2009, The Idea of Human Rights, Oxford, Oxford University Press.

Bentham, J., 1987, "Anarchical Fallacies; Being an Examination of the Declaration of the Rights Issued during the French Revolution", en J. Waldron (comp.), None-Sense upon Stilts, Routledge, Londres, pp. 46-69.

Blake, M., 2001, "Distributive Justice, State Coercion and Autonomy", Philosophy and Public Affairs, vol. 30, no. 3, pp. 257-296.

Clapham, A., 2006, Human Rights Obligations of Non-State Actor, Oxford University Press, Oxford.

Cohen, J., 2010, The Arch of Moral Universe, Harvard University Press, Cambridge, Mass.

Donelly, J., 1986, "International Human Rights: A Regime Analysis", International Organization, vol. 40, no. 3, pp. 599-639.

Dworkin, R., 2013, "A New Philosophy for International Law", Philosophy and Public Affairs, vol. 41, no. 1, pp. 2-30.

Gewirth, A., 1982, Human Rights: Essays on Justification and Applications, The University of Chicago Press, Chicago.

Gilabert, P., 2011, "Humanist and Political Perspectives on Human Rights", Political Theory, vol. 39, no. 4, pp. 439-467.

${ }^{11}$ Una versión preliminar de este artículo fue presentada en el Workshop sobre Filosofía Política realizado en Carlos Paz (Córdoba, Argentina) en noviembre de 2015. Deseo agradecer a sus participantes por sus valiosos aportes. Asimismo, deseo agradecer a Hernán Bouvier, Rodrigo Sánchez Brígido, Juan Iosa, Moisés Vaca, Marcelo Alegre y dos dictaminadores anónimos de Crítica. 
Glanville, L., 2012, "The Responsibility to Protect Beyond Borders", Human Rights Law Review, vol. 12, no. 1, pp. 1-32.

Griffin, J., 2008, On Human Rights, Oxford University Press, Oxford.

Hobbes, T., 1982, Leviathan, Penguin, Londres.

James, S., 2003, "Rights as Enforceable Claims", Proceedings of the Aristotelian Society, vol. 103, pp. 133-147.

Kant, I., 1996, The Metaphysics of Morals, en M. Gregor (comp.), Practical Philosophy, Cambridge University Press, Cambridge.

Lafont, C., 2010, "Accountability and Global Governance: Challenging the State-Centric Conception of Human Rights", Ethics and Global Politics, vol. 3, no. 3, pp. 193-215.

Locke, J., 1988, Second Treatise of Government, en P. Laslett (comp.), Two Treatises of Government, Cambridge University Press, Cambridge.

Meckled-García, S., 2005, "Neo-Positivism about Rights: The Problem with 'Rights as Enforceable Claims'", Proceedings of the Aristotelian Society, vol. 105, no. 1, pp. 143-148.

Montero, J., 2016, “Do Human Rights Derive from Natural Rights? The State of Nature, Political Authority and the Natural Right to Independence", The Philosophical Forum, vol. 47, no. 2, 2016, pp. 151-169.

__ 2014, "Human Rights, International Human Rights and Sovereign Political Authority: A Draft Model for Understanding Contemporary Human Rights", Ethics and Global Politics, vol. 7, no. 4, 2014, pp. 143162.

, 2010, "Do Affluent Countries Violate the Human Rights of the Global Poor?", Global Justice: Theory, Practice, Rhetoric, vol. 3, 2010, pp. $22-42$.

—_ inédito, "Human Rights, Personal Responsibility and Human Dignity: What Are Our Moral Duties to Promote the Universal Realization of Human Rights", Human Rights Review (en prensa).

Morsink, J., 1999, The Universal Declaration of Human Rights, University of Pennsylvania Press, Philadelphia.

Nagel, T., 2005, "The Problem of Global Justice", Philosophy and Public Affairs, vol. 33, no. 2, pp. 113-147.

Nickel, J., 2014, "Human Rights" [pdf de la entrada], Stanford Encyclopedia of Philosophy, ed. Edward N. Zalta, disponible en línea en <http:// plato.stanford.edu/entries/rights-human/>.

—_, 2006, “Are Human Rights Mainly Implemented by Intervention?", en R. Martin y W. Reidy (comps.), Rawls's Law of Peoples: A Realistic Utopia?, Blackwell, Malden, pp. 263-275.

Nozick, R., 1974, Anarchy, State and Utopia, Basic Books, Nueva York.

Nussbaum, M., 2002, "Capabilities and Human Rights", en P. De Grieff y C. Cronin (comps.), Global Justice and Transnational Politics, The MIT Press, Cambridge, Mass., 2002, pp. 119-149.

, 1997, "Human Rights Theory: Capabilities and Human Rights", Fordham Law Review, vol. 66, pp. 273-300. 
O’Neill, O., 2003, Bounds of Justice, Cambridge University Press, Cambridge.

Pogge, T., 2002, World Poverty and Human Rights, Polity Press, Cambridge.

Rawls, J., 1999a, The Law of Peoples with “The Idea of Public Reason Revisited", Harvard University Press, Cambridge Mass.

—_ 1999b, A Theory of Justice, edición revisada, The Belknap Press, Boston.

Raz, J., 2010, "Human Rights without Foundations", en S. Besson y J. Tasioulas (comps.), The Philosophy of International Law, Oxford University Press, Oxford, pp. 321-338.

Ripstein, A., 2009, Force and Freedom: Kant's Legal and Political Philosophy, Harvard University Press, Cambridge, Mass.

Salomon, M., 2007, Global Responsibility for Human Rights, Oxford University Press, Oxford.

Sangiovanni, A., 2008, "Justice and the Priority of Politics to Morality", The Journal of Political Philosophy, vol. 16, no. 2, pp. 137-164.

Tasioulas, J., 2009, “Are Human Rights Essentially Triggers for Intervention?", Philosophy Compass, vol. 4, no. 6, pp. 938-950.

Valentini, L., 2012, "Human Rights, Freedom, and Political Authority", Political Theory, vol. 12, pp. 573-601.

Wellman, C., 2011, The Moral Dimensions of Human Rights, Oxford University Press, Oxford.

Aceptado el 22 de enero de 2016; revisado el 8 de septiembre de 2016; aceptado el 31 de octubre de 2016. 